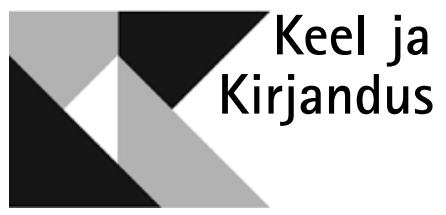

\title{
KOLM KONGRESSI
}

\section{ENSV Kirjanike Liidu ajaloost aastatel 1954-1966}

\author{
SIRJE OLESK
}

\section{Komme pidada kongresse}

$\mathrm{K}$

irjanike kongress ei ole iseenesest nõukogulik nähtus, aga viis, kuidas neid Eesti NSV-s peeti, on läbi nõukogude aja olnud üsna spetsiifiline, st nõukogulik. Samamoodi peeti ka kunstnike, heliloojate, kolhoosnike jne kongresse. Viimane, IX kirjanike kongress Eesti NSV-s toimus 1986. aasta aprilli lõpus, just neil soojadel kevadpäevadel, kui üles lendas radioaktiivne pilv Tšernobõlis. Järgmine kongress oleks pidanud olema viie aasta pärast, 1991. aastal. Siis seda enam ei peetud, vaid just sel aastal muudeti liidu nime: ENSV Kirjanike Liidust sai Eesti Kirjanike Liit. Kümnes kirjanike kongress jäigi pidamata, viimane suurem kokkusaamine Toompeal oli loomeliitude ühispleenum 1988. aasta aprilli alguses. Uus pleenum 2013. aastal oli pigem nostalgiline koopia kui iseseisva tähendusega sündmus. Ka niisugusele foorumile leiab analoogi nõukogulikus kultuuris: 1945. ja 1948. aastal peeti Tallinnas intelligentsi I ja II kongress; 28. oktoobril 1957. aastal oli Toompea lossi istungite saalis loovintelligentsi nõupidamine jms. Siis olid need muidugi propagandaüritused, mille tähendus ka omas ajas oli hoopis teine.

1977. aastal loodi Euroopa kirjanike ühenduste katusorganisatsioon Euroopa Kirjanike Kongress (EKK; European Writers' Congress), mille liige on EKL aastast 1992. 
Kongresse on pidanud asutamisest siiani ka niisugune auväärne literaatide organisatsioon nagu PEN-klubi.

Eesti kirjanikud pidasid kongresse juba enne oma organisatsiooni ametlikku asutamist: kirjanike I kongress oli 1919. aastal, II kongress 1920. aastal (siis valiti kirjanikkude keskkomitee) ja kolmas - asutamiskongress - 8. oktoobril 1922. Rohkem kongresse ei peetud. 19. oktoobril 1940 kuulutasid uued võimud Eesti Kirjanikkude Liidu likvideerituks. Selle asemel alustas tööd Eesti Nõukogude Kirjanike Liidu organiseerimistoimkond. Siis algas sõda ja organiseerimistoimkonna inimesed läksid Nõukogude Liidu tagalasse.

Eesti kirjanike ühendus, mis kandis kuni 1958. aastani nime Eesti Nõukogude Kirjanike Liit (ENKL), asutati Moskvas eesti nõukogude kirjanike I konverentsil 8. ja 9. oktoobril 1943. Tallinnas peeti 24.-26. novembril 1946. aastal ENKL-i I kongress, mida hiljem hakati nimetama II kongressiks ja esimese au sai endale 1943. aastal Moskvas peetud konverents. See I või II kongress 1946. aastal avati vastselt taastatud Estonia kontserdisaalis ja selle sisuks oli tollase esimehe Johannes Semperi pikem kõne, tervitused ja kontsert (Tuglas 1997: 30).

Loomeliidu kongress oli ENSV-s pidulik ja nähtav sündmus, mida kajastati ulatuslikult EKP ja MN häälekandjas Rahva Hääl ja veel põhjalikumalt ajalehes Sirp ja Vasar (enamasti tehti sel puhul ajalehe erinumber). Kirjanike kongresside materjale avaldati veel ka liidu ajakirjas Looming. Kongressidele kutsuti külalisi kõigist vennasvabariikidest, seal oli palju liturgilist retoorikat, partei ja valitsuse tervitusi, NLKP KK valimine aupresiidiumisse, kongressi lõpus vastu võetud otsus või resolutsioon vms. Koos külalistega korraldati kirjandusõhtuid Tallinnas ja tehti väljasõite, näiteks 1954. aasta varasuvel Kohtla-Järvele, kus kohalikus kultuurimajas toimus kirjandusõhtu vene keeles, ja mujalegi. Seevastu seltskondlik osa näis olevat üsna ideoloogiavaba. Nii on Tuglas oma päevikus II kongressi järel noteerinud: „Kell 10 õhtul algas Kadrioru lossis kongressi lõpubankett. Sadakond osavõtjat. Palju lauakõnesid. Lõbus öö" (Tuglas 1997: 31).

\section{Kolmas kongress 8.-10. juunil 1954}

Kongress oli esimene vabama vaimuga kokkusaamine pärast Stalini surma. See toimus Tallinna kesklinnas Harju tänaval, selleaegses Ühingu Teadus kesklektooriumi saalis.

Seda kergemat ja vabamat vaimu vahendab Paul Kuusbergi mälestuskild 1963. aastast: „Soe, päiksepaisteline juuni alguse päev. [---] Siin on äsja Schmuulist Smuuliks saanud püsimatu Juhan, vaatab ringi tugevalt-maamehelikult jalgu maha toetav Aadu Hint, teravmeelitseb alles üsna nooruki moega uudishimulik Uno Laht, seisab endamisi muigav turjakas Egon Rannet, hallipäise Erni Krusteniga vestleb alati sõna- ja tegudeerk Rudolf Sirge, tagasihoidlikult hoiab end seina äärde kadunud Karl Kivi, lõõbib-norib nalja armastav Lembit Remmelgas, kuulab-kostab muutumatult delikaatne Paul Rummo. [---]

Koosolekut juhatav Juhan Smuul laotab presiidiumilaua taga poolnaljatades, poolnõutult-abitult käsi ja kurdab, et kuidas sa hoiad korda ja pead vastuvõetud reglemendist kinni, kui Laosson ja Sõgel aega ei arvesta ja kõnetoolist ära ei lähe. [---] Kongress naerab. Tigedust ei ole" (Kuusberg 1967: 158-159). 
Kirjanike liidu esimeheks oli siis juba kolm aastat olnud Juhan Schmuul, kes just sel ajal muutis oma perekonnanime Smuuliks. Kirjanike liidu juhtkonnast oli minema saadetud Magnus Mälk. Teine kuri mees Max Laosson oli 1953. aastal saanud lahti kunstide valitsuse juhataja kohalt ja jäänud vabakutseliseks literaadiks ning aastatel 1950-1956 õppis Moskva Gorki-nimelise Kirjandusinstituudi kaugõppes. Friedebert Tuglas, Johannes Semper, Kersti Merilaas, August Sang ja teised 1950. aastal kirjanike liidust välja visatud kirjanikud olid veel liidu liikmeteks ennistamata, aga vähemalt Tuglas on kongressil kohal olnud. Oma päevikusse on ta kirjutanud: „Ettekanded enamasti tühised, isiklikud arveteõiendused. Ei ühtki tõelist „kirjaniku-kuju” ega „autoriteeti”. Näib aga, et vaen Semperi ja minu vastu on loidumas” (Tuglas 1997: 57).

Kirjanduselu elavnemine toimus praeguselt kauguselt vaadates siiski arglikult ja vaevaliselt. Varasem hirmuõhkkond leevenes aeglaselt, kuid see leevenes siiski, eriti kui Siberist hakkasid tagasi tulema sinna saadetud vanad kaaslased või uued ja tegusad „noorkirjanikud” (nagu Jaan Kross). Nemad kartsid vähem ja nende jaoks olid siinsed metsikused jäänud kaugeks. Küll olid neist tagasitulemistest häiritud inimesed, kes vahepeal Eesti kultuuripõllul olid toimetanud ja neid sigadusi korraldanud, nii et pingeid jätkus ka sinna vabamasse atmosfääri. Natuke vabamat vaimu võisid levitada ka need kirjanikud, kes 1954. aasta detsembri lõpus olid käinud Moskvas üleliidulisel kirjanike kongressil, mis toimus esmakordselt pärast 1934. aastal peetud I üleliidulist kirjanike kongressi. Juba see fakt ise - kongressi korraldamine - oli märk suure surve leevenemisest. NSVL Kirjanike Liidu juhatusse olid Eestist valitud August Jakobson, Hans Leberecht ja Juhan Smuul; viimane kui ENSV esikirjanik valiti ka NSVL KL juhatuse 42-liikmelisse presiidiumisse.

21. märtsil 1955. aastal oli Eestis kirjanike liidu juhatuse koosolek, kus arutati läbi „suure kongressi” otsused. Ettekande tegi juhatuse sekretär Lembit Remmelgas, kes oma esinemise lópus ütles, et tuleks uuesti üle vaadata vanad juhatuse otsused, mis olid tehtud Johannes Semperi, August Sanga ja Kersti Merilaasi suhtes. Selline ettevaatlik sõnastus tähendas ilmselt viidet, et aeg oleks hakata mõtlema nende liidu liikmeks tagasi kutsumisele. Aadu Hint on küsinud, miks nimetab Remmelgas ainult kolme nime, kui väljavisatuid oli ometi rohkem. Ja loetleb: kus on Metsanurk, kus Alver, Tuglas, Viiding, Toomingas, Kibuvits? „Me ei tohi ignoreerida Tuglast, meie vaenlased Rootsis ainult rõõmustavad selle üle."

Mart Raud tuletas meelde, et Moskvas ja Leningradis ollakse palju aktiivsemad kui Eestis. Seal olla loodud uued kirjandusajakirjad (Junost, Neva, Družba Narodov) - kus on vastavad väljaanded Eestis? Etteruttavalt võib öelda, et varsti need tõesti tulid ka Eestisse: 1957. aastal asutati Loomingu Raamatukogu ja 1958. aasta veebruaris ilmus Keele ja Kirjanduse esimene number.

Protokollitud on Max Laossoni repliik: „Seoses mõne kirjaniku tagasivõtmisega liitu asetatakse küsimuse alla Noor-Eesti kohta antud seisukoht. Samuti olen märganud iroonilist tendentslikku suhtumist isiklikult minusse." ${ }^{2}$ Selle peale küsis Hint otse: kas Tuglas võiks olla kirjanike liidu liige, mille peale Laosson vastas, et vahest võikski olla, aga reservatsioonidega.

\footnotetext{
${ }^{1}$ ENKL juhatuse koosoleku protokoll 21. märtsil 1955. ERA R-176, n 1, s 162.
}

${ }^{2}$ ENKL juhatuse koosoleku protokoll 21. märtsil 1955. ERA R-176, n 1, s 162. 
Remmelgas sõnastas protokollikõlbliku lahenduse: tuleb parandada mõnesid kirjanike liidu juhatuse varasemaid samme, aga ei tule hakata revideerima parteilist kriitikat. $^{3}$

Sama aasta aprillikuus on võetud kirjanike liidu liikmeks hulk uusi või noori kirjanikke (Egon Rannet, Mai Talvest, Muia Veetamm, Otto Samma, Holger Pukk), aga siis seistakse taas silmitsi selle valusa probleemiga, mida teha kunagi välja visatud kirjanikega. 7. aprillil 1955 on Johannes Semper esitanud avalduse enese taastamiseks kirjanike liidu liikmena. Sekretär Lembit Remmelgas seletab, et tema olevat uurinud järele, mis tegelikult juhtus 1950. aasta kevadel. Semperi liidust väljaviskamisele olla olnud hulk õigeid põhjendusi, kuid olla esitatud ka selliseid süüdistusi, millel polnud alust. Semperit ennast sellele koosolekule ei kutsutud, ta visati välja tagaselja. Semperi liikmeõiguste taastamist pooldasid aprillikoosolekul Rudolf Sirge ja Uno Laht. Mart Raud oli viibinud 1950. aastal sellel koosolekul, kus Semper välja visati, ja meenutas, et selline otsus peteti välja Magnus Mälgu poolt ja kogu see lugu olevat olnud Raua sõnutsi paari poliitilise suli inspireeritud operatsioon. Kes need poliitilised sulid olid olnud, protokollist ei selgu ja rohkem kommentaare protokollis ei ole. Koosolekul otsustati taastada Semperi liikmeks olek aastast $1943 .^{4}$

1955. aasta jooksul taastati Friedebert Tuglas, August Sang ja Kersti Merilaas kirjanike liidu liikmeteks, kuid probleem tekkis Nigol Andreseniga: viimane on oma avalduses 18. oktoobrist palunud ennast vangist vabanemise järel ennistada kirjanike liitu. Liidu juhatuse koosoleku protokolli järgi 22. detsembril 1955. aastal on juhatus aga leidnud, et kuna Andresen visati välja enne vangistamist, siis pole tema kõrvaldamine liidust seotud tema vangistamisega ja sellepärast vajab tema juhtum eraldi uurimist. Moodustati komisjon, mille liikmete ülesandeks sai Andreseni väljaviskamise motiivide kontrollimine. Komisjoni liikmeteks määrati Eduard Päll, Paul Rummo, Lembit Remmelgas, Olev Jõgi ja Paul Kuusberg. ${ }^{5}$ Kaua see komisjon asja uurima ei pidanud, sest Andreseni liikmeõigused taastati juba 1956. aastal.

Vabamad meeleolud Eesti kirjanike liidus levisid laiemalt pärast NLKP XX kongressi 1956. aasta veebruaris. Sellega oli uus aeg justkui ametlikultki alanud ja esialgsed märgid kirjanduses olid päris lootusrikkad. 1955. aastal oli ilmunud Smuuli „Kirjad Sõgedate külast”, 1956. aastal Sirge romaan küüditamisest „Maa ja rahvas”. Eriti viimase ilmumine oli väga selge märk suure hulga tabude langemisest (ja ülejäänute seda kindlamalt püsimisest). Sulaaeg oli tulnud ja laienes. Selle üheks märgiks sai diskussioon kirjanduspärandi ümber, mille kokkuvõtteks võiks pidada Remmelga kahte asjakohast artiklit 1956. aastal, mis osaliselt kattusid, kuid olid väljenduslaadilt mõnevõrra erinevad: üks ilmus Loomingus ja teine, ametlikum Rahva Hääles (vt selle kohta Kuuli 2002: 80-81).

Kuid need inimesed, kes olid Eestis 1950. aasta repressioonide taga, kogusid ennast üsna kiiresti. Kõikidel järgnevatel aastatel kuni nõukogude võimu lõpliku kokkukukkumiseni peeti omamoodi kaevikusõda rahvusmeelsete ja ortodokssete kommunistide vahel, kus leerid ei olnud kunagi päriselt selged (sest osa tegelasi liikus nende kahe vahel) ja kus vaheldumisi edenesid kord

\footnotetext{
${ }^{3}$ ENKL juhatuse koosoleku protokoll 21. märtsil 1955. ERA R-176, n 1, s 162.

${ }^{4}$ ENKL juhatuse koosolek 20. aprillil 1955. ERA R-176, n 1, s 162.

${ }^{5}$ ENKL juhatuse koosolek 22. detsembril 1955.
} 
ühed ja siis jälle teised. Nii oli kirjanike liidu IV kongress selgelt reaktsiooniks kolmandale kongressile ja seal üritati vahepeal kaotatud positsioone tagasi võita. Vasturünnak algas 1958. aasta jaanuaris EKP X kongressil, kus parteijuht I. Käbin ${ }^{6}$ ründas „revisjoniste”, kes on teinud katseid „valgeks võõbata kodanliku Eesti rahvavastast korda” (Kuuli 2002: 86).

Kirjanike liidu IV kongress oli alguses planeeritud 1958. aasta septembrikuusse. Septembris kongressi ei toimunud, see lükati detsembrisse. Kõik said aru, et Moskvas peeti ägedat võimuvõitlust, mille keskmes oli Boris Pasternak ja tema romaan „Doktor Živago”. Romaani oli pärast seda, kui kirjastused Venemaal olid selle tagasi lükanud, avaldanud Itaalia Feltrinelli kirjastus 1957. aastal. Nobeli komitee oli andnud Pasternakile auhinna 1958. aastal, kuid Pasternak oli sunnitud sellest keelduma. Nõukogude rahvas nimelt mõistis „üksmeelselt hukka” romaani, mida ta lugeda ei saanud. Vastavaid koosolekuid peeti üle Nõukogude Liidu, ka ENSV Kirjanike Liidus 30. oktoobril 1958. aastal, ${ }^{7}$ ja seltsimehed Leberecht, Kuusberg, Raud, Parve, Sikemäe, Skulski, Kurtšavov mõistsid igati ja teravalt ja põhimõtteliselt hukka nii Boris Pasternaki kui ka tema romaani selles ilmneva „nõukogudevastase tendentsi” pärast (Nobeli auhind 1958; artikkel on ilmunud ilma autori nimeta Loomingu „Ringvaate" osas). Õhkkond oli muutunud ka Moskvas.

\section{Neljas kongress 18.-20. detsembril 1958}

See oli esimene kirjanike kongress, mida peeti Toompea lossis ülemnõukogu istungite saalis ja mille kirjanike liidu vanima liikmena avas Tuglas. Kolm päeva varem oli Smuul käinud Tuglase juures ja palunud tal seda teha. Tuglas oli nõustunud ja on vahest ka sellepärast oma muljetes üsna leplik: „Üldiselt valitses kongressil sõbralik mitteisiklik toon (ei või võrreldagi näiteks II kongressiga!)" (Tuglas 1997: 100).

Enne kirjanike liidu kongressi oli 4. detsembril 1958 toimunud EKP Keskkomitees nõupidamine kirjanike-kommunistidega. Seda arutelu juhtis Käbin ja selle teemaks oli kirjandusliku järelkasvu, nn te is e põlvkonna intellige ntsi meeleolude ja suhtumiste analüüs. Analüüs oli murelik, sest „teine põlvkond” (nimetati näiteks Ain Kaalepi, Jaan Krossi, Raimond Kaugveri, Ellen Niidu, Oskar Kruusi, Rein Sepa jt nimesid) oli kirjanike-kommunistide meelest „,ideoloogilistel vildakatel seisukohtadel” (Kuuli 2002: 88-89).

Veel varem (augustis) on kirjanike liidu Tartu osakonna partei algorganisatsioonis arutatud Tartu kommunistide ülesandeid seoses kongressiga. Seal arvati siis, et kongressi keskseks teemaks kujuneb kriitika küsimus. Kriitika nimelt olevat küll vabanenud kärkivast toonist, kuid kaotanud sellega palju oma printsipiaalsest teravusest. Tartu kommunistid Erni Hiir ja Felix Kotta on varemgi olnud mures kaasaegse eesti luule ilutsemise ja apoliitilisuse pärast, mida nad näevad kolleegide Ain Kaalepi ja Kalju Kanguri loomingus. Kotta leiab, et kirjanike liidu luulekonsultant Ellen Niit ei sobi oma kohale,

\footnotetext{
${ }^{6}$ Selleaegsetes ajalehtedes ei anta inimeste eesnimesid. Eesnime algustäht I. sugereerib ometi, et siis kutsuti parteijuhti veel Ivan Käbiniks. Mõni aasta hiljem on ta perioodikas juba J., st Johannes Käbin.

${ }^{7}$ Samal päeval peeti Pasternakki hukka mõistvad koosolekud ka ENSV Heliloojate Liidus ja Kunstnike Liidus.
} 
sest ta pole parteis ja tema luule on täiesti apoliitiline. Hiir leiab, et kirjanike liit pidanuks nooremaid autoreid Loomingu kaudu paremini juhendama. Krossi nimelt saaks veel kasvatada ja enda poole tõmmata, aga Kaalep olevat lootusetu. ${ }^{8}$

Kongressi sisulise peaettekande pidas liidu esimees Juhan Smuul, kes rääkis sellest, kuidas varem juhtžanriks olnud draama asemele on nüüd esikohale tõusnud proosa. Selle esinduslike näidetena nimetas Smuul romaane „Tuuline rand”, „Punased nelgid”, „Noorte südamed”, „Maa ja rahvas” ning Villem Grossi noorsooromaani „Tiivasirutus”. Dramaturgias on suure August Jakobsoni kõrvale suutnud tõusta vaid Egon Rannet silmapaistvate näidenditega „Südamevalu” ja „Kadunud poeg”. Positiivselt nimetas Smuul ka Liivese „Uusaasta ööd”, mis oli staliniste pahandanud, sest selle peategelane oli nn tagasitulija. Seevastu luuletajad nägevat Smuuli meelest elu kitsalt, eriti noorte autorite juures domineerivat hoiak „uksed kinni poliitikale” (siinkohal esitab Smuul negatiivse näitena katke Ain Kaalepi „Sellistest lauludest”). Krossi suhtes on Smuul natuke kahtlev, kuid kokkuvõttes nendib, et Kross arenevat pigem õiges suunas. Parimad luuletajad Nõukogude Eestis on Smuuli meelest Uno Laht ja Johannes Semper. Viimane on kirjutanud oma päevikusse 21. detsembril 1958. aastal:

„Eile lõppes meie kirjanike kongress. Läks libedasti ja asjalikult. Teravusi tekitas veidi ainult Kinostuudioga konflikt ja mõned arusaamatused J. Krossi luuletustega. Paljusid irriteerib ta ideede ähmasus, mitutpidi mõistmine, ta edvistus ja originaalitsemine. [---] Hääletamisel olin ma saanud kõigi poolthääled juhatusliikmete valimisel ja ka Moskva kongressi delegaadiks määramisel. Parteigrupi koosolekul, kus Smuul palus ennast esimeheks mitte enam valida, pani ta ette mind esimeheks valida...." (Semper 2013: 355.) ${ }^{9}$

Hoopis teistmoodi nägi asju selleaegne opositsionäär Nigol Andresen, kes aastaid hiljem on kirjas Ain Kaalepile iseloomustanud IV kongressi mentaliteeti nii: „Sest ülesandeks oli välja juurida kõike andekat ja ilusat, selleks et jääks väga palju ruumi andetuile parasiitidele."10

Maie Kalda on seda aega meenutades hiljem kirjutanud, et Hruštšovi heitlikkus ja uue kunsti ründamine andsid julgust neile, kellele tema võetud suund ei meeldinud. „Mõnigi eesti juhtkriitik ruttas demonstreerima oma näotut valvsust ja detsembris 1958 peetud KL-i IV kongressi kõnetoolist lajatas uue generatsiooni kirjanike aadressil terve seeria poliitiliselt pahasoovlikke hinnanguid" (Kalda 1989: 453).

Siiski ei suudetud „revisjoniste” sellel kongressil lõplikult nurka suruda; järgnev aeg on nende jaoks pigem võidukas. Sula haripunkt paigutub 1960. aastate algusesse, selle märkideks on Eestis 1961. aasta kriitikanõupidamine ja vabavärsipoleemika (vt selle kohta veel: Olesk 2001: 1387-1388; 2014: 1164-1167). Revisjonistlike meeleolude levimist ka Moskvas kinnitab 1962. aasta novembris ilmunud Aleksandr Solženitsõni jutustus „Üks päev Ivan Denissovitši elus", mille Loomingu Raamatukogu juba 1963. aastal avaldas Lennart Mere ja Enn Sarve tõlkes ning Aleksandr Tvardovski eessõnaga. 1964. aasta märtsis käis Eestis Soome president Urho Kaleva Kekkonen, sama aasta

\footnotetext{
${ }^{8}$ KL Tartu osakonna juhatuse koosolek 29. augustil 1958. ERAF 2477, n 1, s 92.

${ }^{9} \mathrm{Vt}$ selle kohta lähemalt Olesk 2014: 1159.

${ }^{10}$ Nigol Andresen Ain Kaalepile 19. II 1966. KM EKLA, reg 1986/84.
} 
suvel oli Jean-Paul Sartre'i ja Simone de Beauvoiri nädalane külaskäik Tallinna, Tartusse ja Pühajärvele. Aga 1964. aasta oktoobris võeti Hruštšov oma kohalt maha ja sellega said sulalised mesinädalad tegelikult otsa.

\section{Viies kongress 16.-18. veebruaril 1966}

Ka seda kongressi, mis algselt oli kavandatud 1963. aasta lõppu, lükati mitu korda edasi. Kuna siis oli parasjagu käimas Hruštšovi poolt välja kuulutatud seitseaastak, sai selleaegne peaettekandja Paul Kuusberg (kes oli sel ajal kirjanike liidu sekretär, esimees oli ikka veel Smuul, kes juhatas kongressi istungeid) ${ }^{11}$ viidata seitsmeaastasele vahele kui ENSV kirjanike oma seitseaastakule. See polnud tegelik põhjus kongress edasi lükata, viimase olid tinginud muutused ja mullistused Moskvas.

Sellegi kongressi materjalid avaldati Loomingus ning Sirbis ja Vasaras. Ka ajalehes Rahva Hääl oli kongress kõigil päevadel avalehel (Rahva Hääl 17.-22. II). Nüüd materjale üle vaadates tuleb tunnistada, et kõige parem indikaator vaimsuse muutumisest ENSV-s oligi EKP ametlik häälekandja, ajaleht Rahva Hääl, kus seekord oli kongressi kajastus varasematega võrreldes ebatavaliselt vaba ja normaalne. Kongressi eel korraldas ajaleht mitmel nädalal arutelu, kongressi päevadel avaldati iga päev informatsiooni kongressi käigust ja fotosid kirjanikest, lehes ilmusid ka ulatuslikud ülevaated ettekannetest ja kongressi lõppemise järel põhjalikud ülevaated sõnavõttudest. Ja see ei olnud ainult kroonuretoorika, mida muidugi oli ka, vaid kohati päris inimlik asjade arutamine.

Bernhard Viiding ja Mihkel Loodus on refereerinud kongressi sõnavõtte (Viiding, Loodus 1966). Sellest ülevaatest paistab juba väga selgelt „stalinistide" ja teiste vastasseis. Endel Sõgla katsed kaitsta Egon Ranneti uusimat näidendit, mida oli kritiseerinud külaline Moskvast, ja märkused ettekannete sisu kohta leidsid sõnavõtjate selge hukkamõistu, nii nagu ka Eduard Pälli kriitika „Võla” ja „Monumendi” aadressil. Siinses ajakirjas on ehk huvitav viidata veel Helene Siimiskerile, kes kõneles sellest, kuidas erialane kirjandus teistes keeltes tuleks teha kirjanikele ja kirjandusteadlastele kättesaadavaks.

See oli ka kongress, kus vormistati põlvkonnavahetus eesti kirjanduselus. Kirjanike liidus jäid küll ametisse sinna sulaajal ja natuke ennegi tõusnud mehed (naisi on ENSV KL juhatuses sel ajal ainult üks või kaks), kuid kirjanduses kehtestas ennast hilinejate põlvkonna kõrval (Kross, Kaalep ja Niit) sõja eel ja ajal sündinute põlvkond Enn Vetemaast ja Mats Traadist Paul-Eerik Rummo ja Viivi Luigeni.

\section{Kokkuvõtteks}

Kirjanike kongressid (nagu ka ilmselt heliloojate, kunstnike, arhitektide jne kongressid) olid õitsvas sotsialismis tähtsad sündmused, mida kajastati laialt ja millele elati kaasa. Kongress ise on ilmselt vaid märk, peegeldus selle kohta, kui tähtis oli nõukogude võimu jaoks loominguline liit kui niisugune. Oleks oluline vaadata lähemalt kirjanike liidu kõrval ka teiste loominguliste liitude

\footnotetext{
${ }^{11}$ Kuusberg oli kongressi ajal haige, tema ettekanne loeti ette.
} 
tegevust ja eriti seda, kuidas peegeldus loomingulise liidu kongressidel selle liidu paraadpool (sest muud ju näidata ei soovitud). Siin oli ilmselt sünkroonsust, sest korraldused Moskvast kehtisid ühtemoodi kõigi loomeliitude jaoks ja erinevused liitude tegemistes on ilmselt need, mille kaudu saab hinnata iseseisvuse määra. Niisama oluline kui viis, kuidas kirjanike liidu tegemisi avalikkusele esitati, on ka see, keda loomingulistest inimestest mingil ajal hinnati ja mingil ajal taas maha vaikiti või represseeriti. Siingi märkab olulisi erinevusi.

Kirjanike hierarhias oli kõige kõrgem ENSV rahvakirjaniku tiitel. 1966. aastaks oli see omistatud kaheksale kirjanikule, kellest sel ajal oli elus neli: Friedebert Tuglas, Johannes Semper, Juhan Smuul ja Aadu Hint. ${ }^{12}$ Tegelikult oli neist läbini nõukogulik kirjanik ainult Smuul, teised olid oma teoseid avaldanud juba enne sõda. Omal kombel olid nad kõik ju ka veel aktiivsed, Tuglas küll rohkem sümbolina. Kindlasti oli aktiivne ka Hint, kuid erinevalt teistest ei ole ta kunagi juhtinud kirjanike liitu ning pole olnud selle presiidiumis või sekretariaadis. Kas segas ta seal kedagi (Smuuli?) või tõrjuti teda tema temperamendi pärast, ei oska öelda. Semper oli põlu alt pääsemisest alates kuni surmani kogu aeg kirjanike liidu juhatuses, esindas ENSV-d Lenini preemiate komitees ning oli paljude välisdelegatsioonide alatine liige: osalt kindlasti sellepärast, et oskas rääkida võõrkeeli ja käituda härrasmehena ning teisalt oli ta ka ideoloogiliselt lojaalne ja asjaajamistes korrektne. Ilmselt ei olnud seda alati Juhan Smuul, kuid teda kaitses tema Lenini preemia.

Vaatame veel ENSV Kirjanike Liidu juhtkonda kuni kuuekümnendate aastate keskpaigani. Kauaaegne esimees oli Juhan Smuul, kauaaegne sekretär Lembit Remmelgas, kes oli küll 1960. aastal taandatud liidust kinostuudiosse. Filmistsenaariumide eest maksti sel ajal suurt raha, ka siis, kui nendest lõpuks filme ei tehtudki, seepärast käis ka kinostuudio ümber kogu aeg mingi intriigitsemine, mis on halvasti dokumenteeritud, kuid mis vääriks eraldi uurimist ja käsitlemist. Sel ajal tuli kirjanike liitu ja Loomingusse tööle Paul Kuusberg, kes oli vaheldumisi kas sekretär või Loomingu peatoimetaja. Tartus oli kaua ametis Erni Hiir, siis lühikest aega Johannes Feldbach ja alates 1962. aastast kuni oma surmani 1982. aastal Kalju Kääri. Kõik nad olid NLKP liikmed, parteitöös karastunud inimesed, kes aga enamasti suhtusid hoolivalt oma kolleegidesse, muidugi neis raamides, mida partei ja valitsus neile seadnud oli. Seda näitab kujukalt Tartus nn Alliksaare skandaal, kus muidu inimlik Kääri Alliksaart ei kaitsnud. Ainsa parteituna oli kirjanike liidu juhtkonnas, sageli sekretärina, ametis Rudolf Sirge. Parteikoosolekutel olid aktiivsed Nigol Andresen ja Uno Laht, keda aga juhtorganitesse üldiselt ei valitud. Miks, võib vaid aimata. Veel käisid aeg-ajalt kirjanike liidu parteikoosolekutel Endel Sõgel ja Ants Saar, keda liidu juhtorganitesse ei valitud mitte kunagi, kuid keda ei saanud ka päriselt ignoreerida. Nii võikski jutustuse ENSV Kirjanike Liidu ajaloost üles ehitada ka narratiivina headest ja pahadest kommunistidest, kes omavahel aastakümneid võitlevad, kuni Moskvast (jälle Moskvast!) alguse saanud perestroika head võidule aitab.

${ }^{12}$ Veel oli see tiitel omistatud Oskar Lutsule (1945), August Jakobsonile (1947), Anna Haavale (1954) ja Ernst Peterson-Särgavale (1957). 


\section{Arhiiviallikad}

ENSV Kirjanike Liidu juhatuse koosolekute protokollid. - ERA R-176, n 1.

ENSV Kirjanike Liidu Tartu osakonna juhatuse koosoleku protokollid. - ERA F-2477, n 1.

Nigol Andreseni kirjad Ain Kaalepile. - KM EKLA, reg 1986/84.

\section{Kirjandus}

K a l d a, Maie 1989. Kirjandus ja sotsiaal-poliitiline süsteem. - Keel ja Kirjandus, nr 8, lk 449-457.

K u u li, Olaf 2002. Sula ja hallad Eesti NSV-s. Kultuuripoliitikast aastail 19531969. Tallinn.

K u u s b e r g, Paul 1967. Ajast, maailmakodanikust ja muust. Tallinn: Eesti Raamat.

Nobeli auhind 1958 = Nobeli auhind, poliitika ja Pasternak. - Looming, nr 11, lk 1759-1762.

O l e s k, Sirje 2001. Vabavärsi kolmekrossiooper. - Looming, nr 9, lk 1384-1397.

Ole sk, Sirje 2014. Kuuekümnendad aastad ENSV Kirjanike Liidus: muutuste aeg. - Looming, $\mathrm{nr}$ 8, lk 1154-1174.

Rahva Hääl nr 40-44; 17. II-22. II 1966.

S e m p e r, Johannes 2013. Päevaraamatud. Tartu: Ilmamaa.

T u g l a s, Friedebert 1997. Eluloolisi märkmeid II. 1944-1959. Litteraria. Eesti kirjandusloo allikmaterjale. Vihik 12. Tartu: Virgela.

V i i d i n g, Bernhard, L o o d u s, Mihkel 1966 = Eesti NSV kirjanike kongressi sõnavõttudest. Põgus ülevaade otsese ja kaudse kõne vahendusel. - Rahva Hääl, nr 44, 22. II 1966.

\section{Three congresses: On the history of the Writers' Union of the Estonian SSR in 1954-1966}

Keywords: power, literature, Writers' Union, Soviet cultural policy, cultural policy in the Estonian SSR

One of the manifestations of Soviet cultural policy involved spectacular congresses of the creative unions, held according to a traditional scenario. Such congresses (of composers, artists, writers, as well as, e.g., of collective farmers) were always very ceremonious, with a lot of rhetoric eulogizing the authorities; some, if not all members of the Central Committee of the Communist Party of the Soviet Union were elected to the Honorary Presidium of the congress, a letter was addressed to the congress by the Bureau of the local (Estonian) Communist Party or by some other such organ, a congress resolution was adopted, containing a rhetorical answer to the letter of salutation received from the Communist Party etc. The keynote speech was followed by co-reports on separate genres and by short speeches. The congress usually lasted 2-5 days and ended, invariably, with a banquet. The congresses were extensively covered in the official press. 
The article takes a closer look at three congresses of the Writers' Union of the Estonian SSR, which took place in 1954 (3rd Congress), 1958 (4th Congress) and 1966 (5th Congress). The Estonian Writers' Union founded in 1922 was dismissed in 1940. A new union for the writers of the Estonian SSR was established in Moscow in 1943. As that founding event was first called a conference the first Congress of the new union was officially held in Tallinn in 1946. Later, however, Moscow began to count the Estonian writers' congresses right from the founding gathering, which shifted the number of the 1946 Congress to 2nd, etc. The first congresses were strictly Stalinist parading events, which had little to do with literature. The Congress of 1954, being the first after Stalin's passing away, was important as the first harbinger of more liberal times to come. The Fourth Congress held five years later was used by the authorities as a counter-attack to defend the so-called Soviet values. The atmosphere of the Fifth Congress was relatively free and its course was extensively covered in the official press. At the same time, no taboos practised by the Soviet censorship had been lifted. An examination of the showtime as well as backstage of the writers' congresses during that 12-year period gives a fascinating insight into the literary-political struggles of the time as well as into the personalities responsible for the then face of Estonian literature and the Writers' Union of the ESSR.

Sirje Olesk (b. 1954), PhD, University of Helsinki, Lecturer in Estonian Culture and Literature,sirje.olesk@helsinki.fi 